\title{
XLIV. On a practical point in connexion with the comparison of resistances
}

\section{W.N. Shaw M.A.}

To cite this article: W.N. Shaw M.A. (1884) XLIV. On a practical point in connexion with the comparison of resistances, Philosophical Magazine Series 5, 17:107, 398-400, DOI: 10.1080/14786448408627531

To link to this article: http://dx.doi.org/10.1080/14786448408627531

曲 Published online: 29 Apr 2009.

Submit your article to this journal $\lceil\pi$

Џ Article views: 2

Q View related articles $₫$ 
XLIV. On a Practical Point in connexion with the Comparison of Resistances. By W. N. SHaw, M.A., Emmanuel College, Cambridge*.

[Plate XIII.]

THE most accurate method at present in use for the comparison of two resistances differing only by a small fraction of an ohm, is that suggested by Prof. Carey Foster (Journal Soc. Tel. Engineers, 1872). It is a method peculiarly suitable for the comparison of standards of resistance and the determination of temperature-coefficients of coils. It gives the difference of two resistances compared, free from errors, which might arise in the ordinary sliding-wire Wheatstone-bridge arrangement, from uncertainties as to the contacts of the ends of the slide-wire, or from the resistance of the connecting-pieces between the ends of the slide-wire and the electrodes of the coils compared. In the process of making a determination by this method, the two coils $\mathrm{X}$ and $Y$ have to be made to interchange their positions, with reference to the other resistances of the bridge ; and it therefore becomes important for the application of the method that the observer should be able to interchange the connexions of the two coils with rapidity and facility.

This is very efficiently and conveniently provided for in the modified form of the slide-wire bridge devised by Dr. Fleming, and described in the third volume of the Proceedings of the Physical Society (p. 174) $\dagger$. With the ordinary form of bridge the interchange is more difficult, for the coils to be compared have generally to be kept in water, and the two pairs of binding-screws of the bridge are a considerable distance apart, and thus the shifting of the coils to change their connexions is a somewhat inconvenient matter.

At the meeting of the Physical Society on Feb. 23, Prof. S. P. Thompson made some suggestions as to the manner in which the ordinary slide-wire bridge might be adapted so that Carey Foster's method could be conveniently applied.

We have, during the past three years, at the Cavendish Laboratory frequently had occasion to make use of the ordinary bridge for comparing coils and determining temperaturecoefficients ; and have accordingly found it necessary to devise some simple arrangement by which the easy and rapid interchange of the resistances under comparison could be provided for.

* Uommunicated by the Physical Society. Read March 8, 1884.

$\ddagger$ Phil. Mag. [5] vol. ix. p. 109. 
I. A simple plan of securing the facility of interchange of contasts is to arrange four mercury-cups in a row, as $1,2,3,4$ in fig. 1, and connect them, as shown in the figure, with the binding-screws $\mathrm{A} B$ and $\mathrm{C} D$ of the bridge by stout copper rods. The mercury-cups should have thick copper bottoms, or, if the arrangement is to be permanent, may be formed conveniently of short bars of copper surmonnted by pieces of india-rubber tube, so that connecting-rods can then be permanently fixed to the copper bars. The electrodes of the coils $\mathrm{X}$ and $\mathrm{Y}$ are inserted at 1 and 3 , and 2 and 4 respectively, or vice vers $\vec{a}$, and their connexions can accordingly be interchanged with very little motion. The electrodes can be kept in contact with the bottoms of the mercury-cups by elastic bands.

This plan of adapting the bridge differs but little from that described by Prof. Thompson, but is, perhaps, somewhat simpler.

II. The second method which we have been in the habit of using requires a more elaborate apparatus, but bas the advantage that the contacts of the electrodes of the coils themselves are not altered during an experiment, the interchange being effected by means of a key. The coils under examination can, indeed, be soldered to projecting parts of the key if necessary, and the requisite contacts are secured by springs pressing down metal tongues into mercury-cups. The advantage of this arrangement is very considerable when experiments are being made by observers who are unfamiliar with the eccentricities of contacts.

The arrangement of the key is shown in plan in fig. 2, and in section in fig. 3. Eight mercury-cups 1, 2, 3, 4, 5, 6, 7, 8 are formed by boring holes in an ebonite plate, about half an inch thick, and serewing copper plates on the back (shown by dotted lines in the figure). These copper plates, which are carefully insulated from each other, connect the eight mercurycups in pairs, and are brought out in tongues A, B, C, D, to which rods, forming connexions with the binding-screws of the bridge, can be soldered, or temporary contacts can be made by means of the mercury-cups formed by drilling the ebonite, as shown in the figure.

To another plate of ebonite, fixed opposite to these cups on the same board, four pairs of thick tongues of copper-I, II, III, IV, V, VI, VII, VIII - are attached, the ends of the tongues forming springs about 6 inches long. At the end of each spring a copper plunger is arranged to dip down to the bottom of the corresponding mercury-cup, into which it is pressed by a spring, $\mathrm{S}$, as shown in fig. 3 . The springs work against the 
crosspiece of wood M, M, and are insulated from the tongues by india-rubber.

A quadruple crank, $Q$, is arranged to be rotated between the supports of the crosspiece $M, M$ by means of the handle $H$. The crank is put under the tongues at the points where they are pressed by the springs. By rotating this crank four alternate plungers (I, III, V, VII) are lifted ont of their mercury-cups, the other four (II, IV, VI, VIII) being pressed in by the springs; or, on turning the crank through $180^{\circ}$, the four tongues (II, IV, VI, VIII) are lifted out and the other four pressed into contact by their springs.

The electrodes of the resistances to be compared are introduced into the mercury-cups $\alpha, \beta$ and $\gamma, \delta$ respectively, or they could be soldered to continuations of the tongues with which these cups are connected.

Thus rotating the crank determines one of the following series of connexions:-

1st position. Contacts..... 1 I. 3 III. 5 V. $7 \mathrm{VII}$. Connexions A $\alpha . \quad \mathrm{B} \beta . \quad \mathrm{C} \%$. D $\delta$.

2nd position. Contacts.....2 II. 4 IV. 6 VI. 8 VIII. Connexions A $\delta$. B $\gamma$. C $\beta$. D $\alpha$.

So that the coils $X$ and $Y$ are alternately connected with $A B$ and $\mathrm{C} \mathrm{D}$, and vice versâ, by a half-rotation of the crank.

It is necessary that any method of interchanging the coils should not alter the resistance of the connexions. It will be seen that the arrangement described is quite symmetrical, and therefore satisfactory in this respect, except for the piece of copper connecting I, II with $\delta$; and the resistance of this, if the copper be fairly thick, is too small to be appreciable.

Cavendish Laboratory, Cambridge,

March 7, 1884.

\section{Note on Hall's Phenomenon. By Herbert Tomlinson, B.A.*}

TN a paper entitled "The Influence of Stress and Strain on the Action of Physical Forces" $\uparrow$, I drew attention to the fact that there is a marked resemblance between the table of "rotational coefficients" drawn up Prof. Hall and that laid down by myself from the results of experiments on the effects

* Communicated by the Physical Society. Read March 22, 1884.

$\dagger$ Phil. Trans. Part I. 1883, p. 168. 
Phil Mag. S. 5.Vol.17. PI Xill

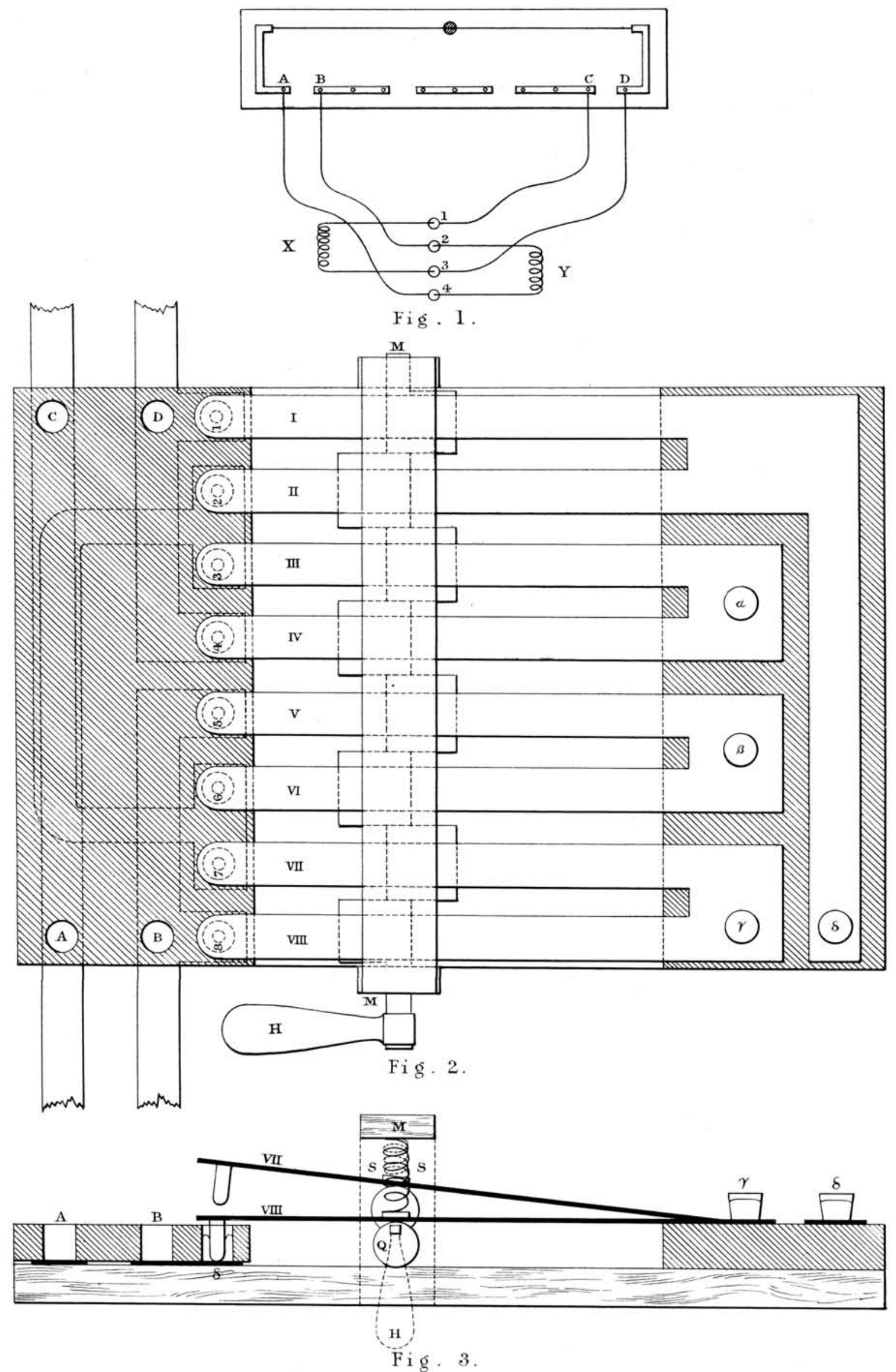

Fig. 3 .

Mintern Bros.lrth. 